\title{
AS DIMENSÕES DA INOVAÇÃO NAS VINÍCOLAS ORGÂNICAS CERTIFICADAS: UMA ABORDAGEM A PARTIR DA VISÃO BASEADA EM RECURSOS
}

DOI: http://dx.doi.org/10.18616/pidi13

Marcos Vinícius Araujo

Email: marcos.araujo@ufrgs.br

Martiele Cortes Borges

Email: martiele.borges@ufrgs.br

Daniela Callegaro de Menezes E-mail: daniela.callegaro@ufrgs.br 


\section{INTRODUÇÃO}

Com o advento da Revolução Industrial, novos formatos foram se instalando nas plantas produtivas, passando do artesanal ao industrial devido às necessidades urgentes na época. No mesmo sentido, a Revolução Verde modernizava a produção no campo para o ganho produtivo por meio do aumento do uso de máquinas, agroquímicos fertilizantes e insumos agrícolas. Com isso, as consequências sociais se alastraram e geraram também conflitos econômicos e ambientais, principalmente em países de terceiro mundo (REDCLIFT; GOODMAN, 1991).

Ao longo dos anos, as questões de sustentabilidade, como a agricultura orgânica, vêm ganhando interesse não só entre consumidores, mas também entre governos e cientistas (HALWEIL, 2006). Essas mudanças são vistas desde os anos de 1980, a partir das preocupações ambientais advindas com o surgimento do terceiro regime alimentar (KLEDAL, 2010). Devido a isso, novas opções de produtos vêm atender a esse mercado mais consciente, de modo que a credibilidade dessas ofertas passa a ser fundamental para garantir o sucesso desses produtos.

Assim, emerge a necessidade de uma regulação que garanta ao consumidor e ao cliente a origem orgânica dos produtos adquiridos, dado que esses não podem ser percebidos imediatamente no momento da compra sem a utilização de selos de identificação. No Brasil, a Lei n $10.831 / 2003$ é responsável por regulamentar os produtos orgânicos. Ela entrou em vigor a partir do Decreto $n^{\circ}$ 6.323/2007 (BRASIL, 2007). A lei dos produtos orgânicos prevê que agricultores familiares cadastrados no órgão fiscalizador não necessitam de certificação para comercializarem diretamente com os consumidores finais em feiras. No entanto, para a venda em redes de varejo e demais pontos de venda, é necessário adquirir o selo de produto orgânico.

Nesse contexto, a indústria vinícola brasileira - que já representa o $15^{\circ}$ produtor mundial (OIV, 2016) - vem buscando inovações em seu setor. A Serra Gaúcha (Rio Grande do Sul) já é responsável pela produção de $90 \%$ do vinho nacional (MELLO, 2016). O Vale dos Vinhedos, região vinífera localizada na Serra Gaúcha, apresenta diversas vinícolas que trabalham com os conceitos de modernização, qualidade, produtividade e competitividade (GOLLO; CASTRO, 2008). Segundo Hayashi Junior (2011), percebe-se a busca pela agre- 
gação de valor ao produto ofertado, considerando que a concorrência com os vinhos estrangeiros impõe dificuldades devido às altas taxas tributárias. Por outro lado, algumas cooperativas brasileiras, produtoras de vinho, têm investido na agricultura sustentável como alternativa para melhorar a imagem da marca e conquistar market share. Para o vinho gaúcho, ainda é necessário trabalhar a comunicação com o público, a educação e a cultura de consumo do vinho, por isso que essas cooperativas estão adotando a produção de vinhos orgânicos como seu produto diferencial.

Para Farina (2003), em mercados onde os consumidores não conseguem atestar a característica do produto por si próprio, a certificação é fundamental - caso esse em que o vinho orgânico está inserido. Dessa forma, os produtores de vinhos orgânicos, ao optarem pela comercialização em redes de varejo, necessitam de selos que atestem esse atributo. Como alternativa para atender às demandas de mercado, pequenos produtores se reúnem em forma de cooperativas para que assim possam se tornar competitivos. Conforme Delarmelina e Salles (2014), a cooperativa reduz os custos da internalização à comercialização, pois diminui os riscos de comportamento oportunista e a incerteza do que os produtores enfrentariam no caso de recorrerem diretamente ao mercado, e maximiza os lucros de seus associados. Assim, os custos com a certificação se tornam impeditivos para que cada associado venda de modo separado o seu produto. Dessa forma, eles optam pela cooperativa.

O conceito de cooperativa é entendido como uma associação autônoma de pessoas unidas voluntariamente para satisfazer suas necessidades econômicas, sociais e culturais comuns e aspirações através de uma empresa de propriedade comum e democraticamente gerida (ICA, s.d.). As cooperativas são reconhecidas pela Lei $n^{\circ}$ 5.764, de 16 de dezembro de 1971, como "[...] sociedades de pessoas, com forma e natureza jurídica próprias, de natureza civil, não sujeitas à falência, constituídas para prestar serviços aos associados." (BRASIL, 1971).

Dessa forma, o cooperativismo se movimenta em torno de uma organização econômica e social participativa entre pessoas (VALENT; SCHMIDT; MACHADO, 2014). Enquanto organização econômica, compreende um agrupamento de ideias e entendimentos, cujo grupo se movimenta para um objetivo específico, associando seus esforços, solidariedade e mutualidade, unidos por uma razão comum, justiça comum, democracia e baseados na autogestão (BUTTENBENDER, 2010). Essa mutualidade e trabalho em comum 
faz com que pequenos produtores se tornem mais competitivos, porém existe uma nova abordagem de trabalho, ou seja, a necessidade de gestão para que a organização possa trabalhar em consonância.

Nesse sentido, a produção se torna um desafio, principalmente quando é certificada, tendo em vista a necessidade de mudanças na organização para assim atender à certificação. Dessa forma, essa pesquisa tem como objetivo mapear as dimensões da qualidade das vinícolas orgânicas certificadas, a partir da visão baseada em recursos. Para compreender isso, este capítulo apresenta o referencial a respeito da agroecologia, da inovação e de seu gerenciamento. Após, é apresentado o método utilizado na pesquisa, seguido do resultado e discussão a respeito do confronto entre o material coletado em campo e a literatura apresentada.

\section{AGROECOLOGIA}

No final do século XX, deparamo-nos com o desafio de aumentar a produtividade e expandir ainda mais o fornecimento de alimentos. Após o término da Segunda Guerra Mundial, a Revolução Verde caminhou rumo ao aumento da produção e da produtividade, intensificando o uso de insumos químicos, desenvolvimento de variedades geneticamente melhoradas, intensificação da irrigação e mecanização, criando políticas para sustentar essas atividades (ALTIERI, 2008). Entretanto, com o passar dos anos, essa intensa produtividade e o uso dos recursos geraram questionamentos entre a sociedade, levando os consumidores a buscarem produtos que usem e agridam o mínimo possível o meio ambiente, tendo em vista as crises ambientais, sociais e econômicas que vêm acontecendo nos últimos anos. Nesse período, o uso de agroquímicos implicou em alterações ambientais e sociais negativas. Mesmo contando com a biotecnologia, a partir de sementes geneticamente modificadas, alguns países não conseguiram progredir após poucos anos de seu uso. Dessa forma, essa alternativa não foi suficiente, visto que o desgaste dos solos, com a utilização dessas técnicas, causou impactos negativos ao meio ambiente (CAPORAL; COSTABEBER, 2004).

A agricultura, mesmo sem a utilização de agroquímicos, gera impactos ambientais, pois a alteração não natural da vegetação adaptada ou nativa já consiste em mudanças no ambiente. Assim, encontrar sistemas agrícolas na- 
turalmente adaptados ao ambiente, não necessitando de insumos externos e recursos não renováveis, torna-se um desafio (ASSAD; ALMEIDA, 2004).

Além disso, outros desafios enfrentados pela agricultura, como a minimização de perdas e desperdícios ao longo do sistema produtivo e a garantia de retorno dos investimentos (econômico); a geração de renda compatível para o produtor rural, com condições de trabalho dignas (social); pluriatividade e multifuncionalidade dos espaços rurais (territorial); e a necessidade de novas tecnologias menos agressivas ao meio ambiente (tecnológico) dificultam a inserção de alternativas menos degradantes ao ambiente (ASSAD; ALMEIDA, 2004).

A Revolução Verde contribuiu para a difusão da consciência a respeito dos impactos ambientais gerados a partir do uso indiscriminado de agrotóxicos, da perda da biodiversidade, além da erosão do solo e da desertificação (ALTIERI, 2008). Nesse sentido, vêm sendo desenvolvidas formas alternativas às anteriores, buscando diminuir os impactos no meio ambiente, assim como a agroecologia ou agricultura sustentável.

Essas técnicas alternativas surgem em meio a crises ambientais e sociais, com o objetivo de conhecer os elementos e processos-chave que regulam o funcionamento dos ecossistemas e estabelecem bases para uma gestão harmônica com o meio ambiente (SANS, 2007).

A agroecologia idealiza a restauração da biodiversidade presente no ambiente, com a intenção de alcançar a autorregulação e a sustentabilidade do sistema agroecológico já que o aumento da biodiversidade, as interações entre o solo, as plantas e os animais podem contribuir naturalmente (ALTIERI, 2008).

O escopo da agroecologia não engloba apenas a agricultura, ela é entendida como um campo de estudo que oferece ferramentas que subsidiam a intervenção na extensão rural de estratégias de desenvolvimento rural sustentável (CAPORAL; COSTABEBER, 2000). A ideia trazida a partir dessa abordagem é de uma produção menos agressiva ao meio ambiente, que proporcione inclusão social e que consiga promover benefícios econômicos aos agricultores envolvidos (GLIESSMAN, 2009).

Portanto, a discussão se transfere da produção de baixo impacto para a preocupação com a saúde humana e ambiental, de maneira a considerar os riscos do uso de agrotóxicos para os consumidores e para os produtores, buscando na agroecologia o aumento da qualidade de vida e de lucros (AZEVEDO; PELICIONI, 2011). Técnicas que prezam pela redução de insumos externos e 
pela conservação dos recursos naturais vêm apresentando potencial no aumento dos rendimentos (NODARI; GUERRA, 2015). Assim, a agroecologia se torna uma alternativa à agricultura convencional, pois visa restaurar o ecossistema e a minimização de recursos externos, possibilitando aos produtores que não possuem recursos financeiros para a aquisição de tecnologias caras a sua permanência no mercado (ALTIERI, 2008).

O processo de ecologização de práticas agrárias se torna necessário na mudança de estratégia convencional para agroecológica, integrando aspectos tanto da agronomia quanto da ecologia (CAPORAL; COSTABEBER, 2004). Nesse processo, a eliminação de alguns insumos externos e produtos químicos é fundamental, pois a agroecologia busca baixa intensidade desses recursos.

Figura 1: Etapas de conversão de um sistema convencional para um sistema agroecológico

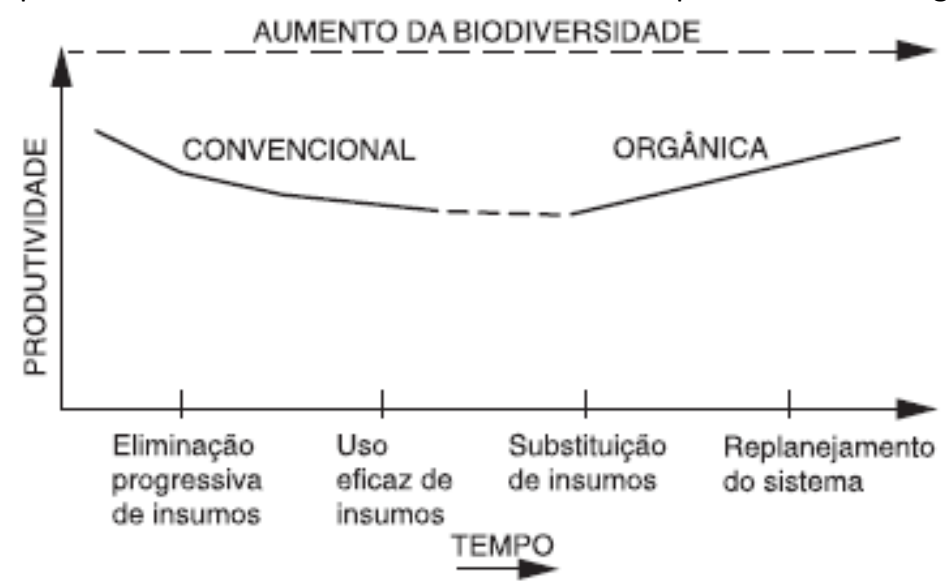

Fonte: Altieri (2008, p. 76).

Conforme a Figura 1, o aumento da biodiversidade acontece ao longo das quatro etapas. A busca pela conversão do sistema passa pelo decréscimo da produtividade até alcançar seu crescimento novamente. Isso ocorre porque essa transição pode levar de um a cinco anos (ALTIERI, 2008). Dessa forma, nesse período, a produção não está nem usufruindo dos benefícios do sistema convencional nem do agroecológico, o que pode levar à desmotivação e à descontinuidade do processo alternativo.

Assim, a agricultura orgânica apresenta características como a eliminação de agrotóxicos e outros materiais sintéticos, utilizando-se de conhecimentos agronômicos, biológicos e mecânicos no manejo do meio rural (GLIESSMAN, 
2009). A produção orgânica brasileira é regulada pela Lei $n^{\circ} 10.831 / 2003$ e regulamentada pelo decreto $n^{\circ} 6.323$ (BRASIL, 2007). Conforme essa Lei, são considerados sistemas orgânicos de produção aqueles que adotam técnicas específicas que objetivam a sustentabilidade, utilizando métodos culturais, biológicos e mecânicos, não utilizando materiais sintéticos em nenhuma das fases da produção até a disponibilização para consumo. Para tanto, a comercialização dos produtos orgânicos, no Brasil, necessita de certificação de entidades reconhecidas oficialmente, exceto quando os produtos de agricultores familiares forem ofertados diretamente aos consumidores finais (BRASIL, 2003).

\section{INOVAÇÃO E O SEU GERENCIAMENTO}

A partir da década de 1980, o desenvolvimento sustentável passou a enfatizar a necessidade de maior equilíbrio entre o meio ambiente, o social e o econômico. Países mais desenvolvidos têm buscado a questão ambiental da sustentabilidade, já os países em desenvolvimento - como o Brasil - têm buscado as questões socioeconômicas (CASAGRANDE JUNIOR, 2004). Dessa forma, as empresas brasileiras buscam a sustentabilidade como forma de inovar.

Schumpeter considera a inovação uma forma nova de fazer algo, ou seja, um novo bem, uma nova forma de produzir, um novo mercado ou uma nova estrutura organizacional. As inovações "shumpeterianas" são motivadas pela percepção de oportunidades de mercados que podem ser transformadas em ganhos superiores pelos agentes econômicos mais audaciosos e efetivos (ZEN; FRACASSO, 2007). Elas são responsáveis pelo aumento da competitividade entre empresas, ocasionando a modificação de suas regras e formas de trabalho, principalmente de gestão, o que passou de modismo a uma questão de sobrevivência (FLEURY; FLEURY, 1995). Nesse sentido, as inovações desempenham um importante papel na firma e também desenvolvem um papel de apoio a inovações, como produto e processo, melhorando a qualidade e a eficiência do trabalho, a troca de conhecimento e o aprimoramento da capacidade de aprendizado para novos conhecimentos e tecnologias (LAM, 2005 apud THE ORGANISATION FOR ECONOMIC CO-OPPERATION AND DEVELOPMET, 2005).

As empresas buscam a inovação como forma de aumentar a sua produtividade, o seu desempenho e competitividade no meio em que estão inseridas. Assim, as empresas que não inovam correm o risco de perder o seu lugar 
no mercado, tendo em vista que não inovar representa uma barreira à sua posição (MOBILIZAÇÃO EMPRESARIAL PELA INOVAÇÃO, 2011; CNI, 2013; NAGANO; STEFANOVITZ; VICK, 2014). A importância de inovar é fundamental, no entanto não é suficiente, pois ela não pode ser entendida como fato isolado, visto que necessita de gerenciamento (TIDD; BESSANT; PAVITT, 2005, 2008).

A gestão da inovação (GI) pode ser entendida como a organização, o planejamento e a coordenação dos fatores essenciais ao desenvolvimento e alcance de resultados inovadores, além de ser o planejamento (TIDD; BESSANT; PAVITT, 2008). Assim sendo, a inovação deve fazer parte de todas as dimensões da organização (SCHENATTO, 2003; TIDD; BESSANT; PAVITT, 2005, 2008; MOBILIZAÇÃO EMPRESARIAL PELA INOVAÇÃO, 2011; CNI, 2013; NAGANO; STEFANOVITZ; VICK, 2014; OSENIEKS; BABAUSKA, 2014). No entanto, para que a empresa possa inovar, é necessário ter os recursos para implementação dessa ideia. A estrutura da empresa é compreendida como recurso de capital organizacional, seja em aspecto informal ou formal, controles, sistemas de coordenação, assim como relações de informações dentro da organização e o relacionamento da empresa com o ambiente (BARNEY, 1991).

Nesse sentido, a Visão Baseada em Recursos (VBR) - campo da estratégia - explica a forma como as firmas podem obter vantagem competitiva sustentável, sendo essa capacidade um pré-requisito para a criação de novos negócios e inovações (ZEN; FRACASSO, 2012). Esses recursos, capacidades e conhecimentos estão subdivididos nas dimensões tácita e explícita. A primeira diz respeito a experiências, pensamentos e sentimentos, que podem ser subdivididos em cognitivos e técnicos; e a segunda é classificada como objetivo base ou baseada em regras (POPADIUK; CHOO, 2006). Popadiuk e Choo (2006) completam que o primeiro está ligado a experiências, pensamentos e sentimentos, divididos em cognitivo e técnicos, os quais estão vinculados a conhecimentos concretos, como know-how e competências específicas, que estão diretamente ligados a inovações em processo e produto.

Nas capacidades e conhecimentos relativos à empresa, encontram-se também os valores e conceitos que são comportamentos intrínsecos a ela. Sete são os valores e conceitos identificados em empresas inovadoras: inovação contínua, capacidade de adaptação do sistema, liderança, valores das pessoas, foco no cliente, aprendizagem contínua e uso do conhecimento (WONG; CHIN, 2007). Contudo, existem outros fatores críticos nas inovações organizacionais e seu desempenho, além dos valores e conceitos, que devem ser discutidos e 
levados em conta para confirmar o impacto dessas mudanças na prática. Nesse sentido, existem indicadores de desempenho da performance da inovação organizacional, que são adotados para demonstrar o conjunto de medidas e analisar o desempenho real da inovação organizacional na empresa (WONG; CHIN, 2007).

Para a definição dos indicadores de desempenho, é importante conhecer as dimensões envolvidas na inovação dentro da organização, tanto vistas como processo quanto como resultado. Conforme a literatura levantada por Crossan e Apaydin (2010), a inovação como processo é pouco recorrente e pouco desenvolvida. Apesar disso, como resultado, ela é o principal foco trazido. Vista como um processo, a inovação precede a visão de resultado e responde a perguntas do tipo "como?". Já a inovação vista como resultado se preocupa com questões do tipo "o quê?" ou "que tipo?". Para fazer essa separação, Crossan e Apaydin (2010) definiram, a partir da literatura, dez dimensões apresentadas na Figura 2.

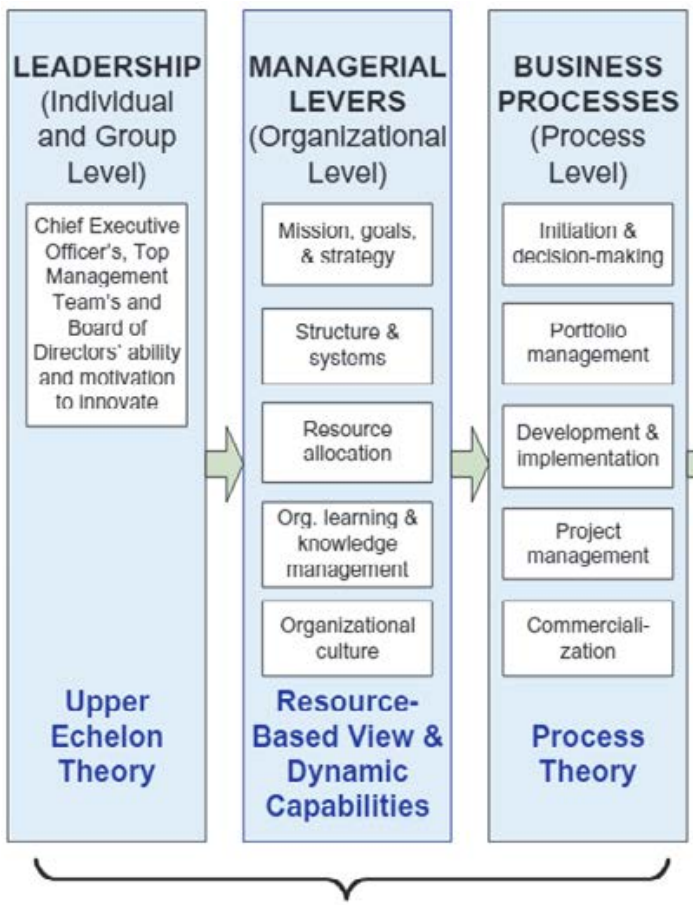

DETERMINANTS OF INNOVATION
Figura 2: A Framework of Organizational Innovation

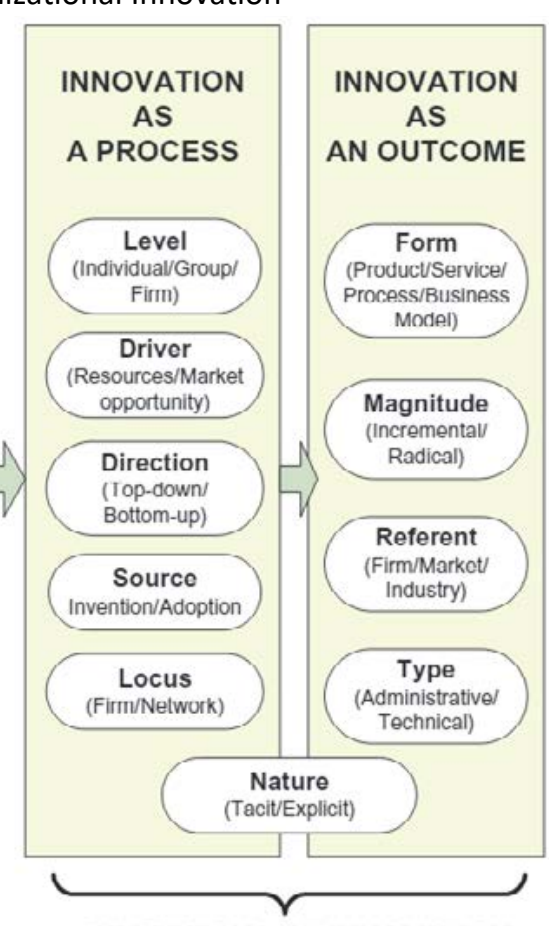

DIMENSIONS OF INNOVATION

Fonte: Crossan e Apaydin (2010, p. 1167). 
Na Figura 2, a inovação como processo apresenta seis dimensões, o nível se refere ao caminho do processo de inovação, ou seja, ocorre em um indivíduo, no grupo ou em toda a firma. A dimensão driver se refere ao impulsionador dessa inovação; em outras palavras, o responsável por sua motivação (pode ser a legislação, a demanda do mercado, entre outros). A fonte (source) explica de onde surge a inovação (interno ou externo), se foi ideação ou se adoção de uma ideia aplicada em outro lugar. A dimensão locus diz respeito à extensão do processo de inovação, que pode ser na firma (processo fechado) ou em rede (processo aberto). A direção da inovação representa onde essa inovação foi gerada, do topo da hierarquia para baixo ou de baixo para o topo. A dimensão natureza da inovação, que também abrange a inovação como resultado, pode ser explícita ou tácita.

Ainda, conforme a Figura 2, a inovação como resultado apresenta cinco dimensões. A forma diz respeito ao tipo de inovação (produto, processo e modelo de negócio); a magnitude se refere ao grau de novidade (incremental ou radical); o âmbito corresponde ao valor de referência (firma, mercado, indústria) e se relaciona com várias outras dimensões; o tipo refere-se às inovações que refletem uma ou mais distinção geral entre estrutura social e tecnologia (técnico e administrativo); e a natureza (tácito ou explícito) pode ser aplicada nas questões "como?" e "o quê?".

Com isso, para compreender as dimensões da inovação nas vinícolas orgânicas certificadas, é necessário entender os recursos que as empresas necessitam para inovar e quais precisam ser aprimorados. Dessa forma, a partir da visão baseada em recursos, é possível entender como essas dimensões se apresentam.

\section{MÉTODO DA PESQUISA}

Este capítulo resultou de uma pesquisa de natureza aplicada, sendo de abordagem qualitativa e com objetivo exploratório. O objetivo de estudos exploratórios é proporcionar uma visão geral a respeito do fato pesquisado (GIL, 2008) e auxiliar o pesquisador a compreender seu problema de pesquisa (MALHOTRA, 2006).

Com o objetivo de mapear as dimensões da qualidade das vinícolas orgânicas certificadas a partir da visão baseada em recursos, foi necessário rea- 
lizar buscas em fontes secundárias para conhecer as empresas pesquisadas e o cenário no qual estão inseridas. Essa etapa indicou duas vinícolas para o estudo, localizadas na Serra Gaúcha - sendo uma em Caxias do Sul e a outra em Garibaldi (RS). Após essa etapa, identificaram-se pontos importantes a serem coletados por meio de entrevistas semiestruturadas com as duas vinícolas que contêm o vinho orgânico certificado em seu portfólio. Essas entrevistas foram realizadas entre maio e junho de 2015. Roteiros sem estrutura fechada e pré-definida são característicos em estudos flexíveis em que a ordem das perguntas (tópicos) pode variar conforme o discurso em cada entrevista, podendo ser individual (MALHOTRA, 2006).

Com o intuito de garantir a validade e a confiabilidade deste estudo, as entrevistas realizadas foram gravadas com a autorização dos entrevistados e transcritas para análise posterior. $\mathrm{Na}$ análise dos resultados, foi apresentado, primeiramente, um tópico com a caracterização das duas entrevistadas para entendimento do contexto em que elas estão inseridas e as características das firmas. Após isso, foi realizado o confronto das entrevistas com a literatura, sendo elegido o modelo de inovação organizacional - proposto por Crossan e Apaydin (2010) - por se tratar de um modelo que integra diversas visões, sendo, então, mais abrangente. Os resultados são apresentados em uma segunda parte, com o confronto do modelo acima aplicado para a Vinícola I e, posteriormente, a análise do modelo aplicado à Vinícola II.

\section{RESULTADO E DISCUSSÃO}

Para fins de melhor entendimento, o resultado da pesquisa será apresentado em duas etapas. No primeiro bloco, um resumo a respeito das duas vinícolas que comercializam vinho orgânico certificado na Serra Gaúcha. No segundo bloco, pretende-se apresentar as discussões dos resultados, com o confronto dos dados coletados e da literatura apresentada, considerando, principalmente, o framework proposto por Crossan e Apaydin (2010). 


\section{CARACTERIZAÇÃO DAS VINÍCOLAS}

A primeira vinícola, para fins deste estudo nomeada Vinícola I, localiza-se no município de Bento Gonçalves (RS). Com a iniciativa de imigrantes italianos, em 1875, iniciou-se a produção de uvas a partir de métodos oriundos da Itália; a partir de 1931, formou-se a cooperativa, tornando-se a maior do Brasil. Devido à busca por sustentabilidade, a vinícola certificou seus processos e atestou sua responsabilidade no Sistema de Gestão no ano de 2006 com a ISO 14.001. A implantação de um sistema de gestão ambiental foi possível graças à sua estrutura organizacional e à sua estrutura física, além da sua alta capacidade de investimento para consolidar sua marca no mercado e investir em market share. Além disso, a vinícola, por meio do departamento de marketing, identificou uma oportunidade de mercado para produtos ecológicos, percebendo que outros concorrentes já estavam entrando nesse mercado. A cooperativa decidiu investir em produtos orgânicos.

A empresa buscou a certificação ECOCERT para que os produtos pudessem ser comercializados nas redes de varejo, pois acreditam que adicionando esses produtos ao seu mix, eles trazem uma boa imagem à marca. Mesmo encontrando dificuldades com o alto custo em adquirir a certificação, a adaptação das instalações, a planta produtiva, o sistema de produção e o treinamento da mão de obra, a empresa fez a transição de convencional para também produzir vinhos orgânicos. Contudo, as dificuldades fizeram com que a cooperativa produzisse apenas no sistema convencional e optasse por terceirizar a produção dos vinhos orgânicos. Mesmo a empresa acreditando que os consumidores desse produto ainda sejam restritos, ela acredita nessa tendência e na imagem positiva que essa comercialização traz a eles.

A segunda vinícola, nomeada Vinícola II, localizada no município de Garibaldi (RS), iniciou suas atividades em 1931. A cooperativa foi fundada por 73 participantes, dos quais três se tornaram presidentes. A cooperativa foi aumentando a produção até alcançar, em 1958, a exportação para o continente Europeu. A vinícola foi crescendo e aumentando o número de cooperados. Além de produção de vinhos e sucos, a cooperativa atingiu destaque na produção de espumantes.

A Vinícola II possui valores relacionados à sustentabilidade. Dessa forma, buscam a utilização da água de forma consciente, oferecem produtos or- 
gânicos (certificados pela ECOCERT), utilizam garrafas mais leves e de material reciclado. Além disso, possuem assistência técnica à disposição do produtor, investimento em tecnologia e capacitação. Também buscam ampliação do market share e reconhecimento da marca no mercado.

A cooperativa iniciou o projeto de produção de orgânicos em 2000. A iniciativa surgiu a partir de três associados que começaram com a produção de 3000 garrafas de vinhos de mesa no ano de 2001. Essas primeiras garrafas foram comercializadas apenas no varejo da cooperativa. No ano seguinte, a vinícola decidiu produzir e comercializar 30 mil garrafas nas grandes redes de varejo. Com o surgimento da regulamentação dos produtos orgânicos em 2003, a cooperativa buscou a certificação, verificando a demanda de consumidores e clientes. Em 2005, certificaram o suco; logo após, em 2006, o vinho branco e o espumante doce. Em 2007, com a parceria de uma vinícola argentina, a cooperativa passou a produzir Malbec e, em 2008, Cabernet Sauvignon. A cooperativa conta com um portfólio de 60 produtos certificados.

\section{ANÁLISE DO RESULTADO}

Mesmo as duas vinícolas tendo o mesmo perfil, sendo grandes cooperativas vinícolas, elas possuem diferentes determinantes e direções para a produção de orgânicos. Nesse sentido, a análise das determinantes e dimensões da inovação organizacional serão tratadas em dois diferentes frameworks, baseados no framework apresentado por Crossan e Apaydin (2010). Tendo em vista que a análise e os principais impactos da adoção da produção orgânica foram em nível organizacional, as determinantes lideranças e os processos do negócio foram retirados da análise para que fizesse a análise ligando as dimensões da inovação dentro do nível organizacional.

Em nível organizacional, mapearam-se impactos das determinantes no processo e no resultado da inovação - dimensões, ou seja, na adoção do processo orgânico ao vinho orgânico. 


\section{FRAMEWORK DE INOVAÇÃO ORGANIZACIONAL NA VINÍCOLA I}

Como é possível verificar na Figura 3, na dimensão organizacional, a empresa apresenta eficiência, excelência, diversificação e estrutura formal, com muitos colaboradores e cooperados, com investimento próprio e investimento em P\&D, capacitando colaboradores e com parceria com a empresa certificadora na adequação aos quesitos para a certificação orgânica. É uma cooperativa que, em seu conceito, movimenta-se em torno de uma organização econômica e social participativa, entre pessoas, cooperados (VALENT; SCHMIDT; MACHADO, 2014).

Quanto às dimensões mapeadas (Figura 3), foi identificada uma inovação em nível de firma, já que foi preciso toda uma readequação da firma para se obter a produção orgânica, que foi motivada (driver) pelas oportunidades de mercado encontradas pelo departamento de marketing, seguindo assim a direção de cima para baixo, ou seja, da alta gerência para os colaboradores de produção e cooperados, os quais tiveram que se readequar para a produção de uvas orgânicas, por não serem de simples adoção. A adoção foi incremental, até que toda a produção de uvas fosse convertida à orgânica e houvesse a adaptação da produção vinícola. A inovação foi tomada em um processo fechado, tecido em nível de firma - pela alta gerência -, fechando assim a dimensão vista como processo, ou seja, como é realizada (CROSSAN; APAYDIN, 2010).

No que diz respeito à natureza da inovação, que é apresentada na figura de Crossan e Apaydin (2010) como uma dimensão da inovação como processo e resultado, Popadiuk e Choo (2006) dizem que a visão baseada em recursos é dividida em tácito e explícito, sendo essa adoção uma regra imposta pela legislação para se certificar como orgânica. Essa dimensão é explícita, baseada em regras. 
Figura 3: Framework de inovação organizacional da Vinícola I
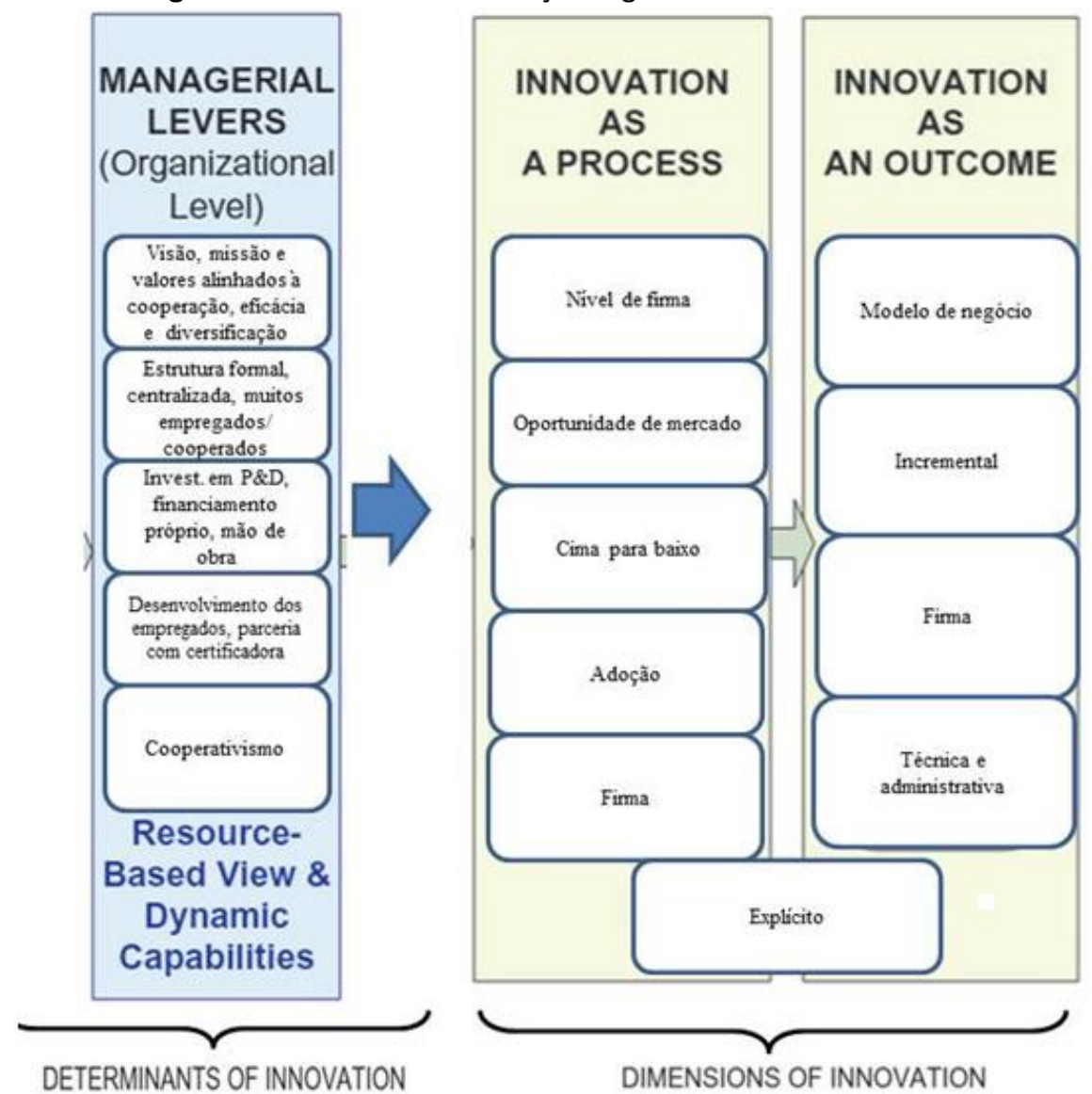

Fonte: Adaptada de Crossan e Apaydin (2010, p. 1167).

Já na dimensão da inovação como resultado, a inovação se apresenta no modelo de negócio, isto é, inovação na lógica como uma empresa opera (OSTERWALDER, 2004), sendo uma inovação incremental, que foi se aplicando ao longo do processo, sendo uma inovação à firma, já que existia no mercado vinhos orgânicos certificados. Na dimensão tipo de inovação, veem-se inovações técnicas e administrativas, já que envolve novos produtos, processos e tecnologias utilizadas para se produzir um determinado produto, uma técnica e também novas atividades de trabalho e dinâmicas de trabalho ligados a aspectos gerenciais, processos administrativos e recursos humanos ligados à organização (CROSSAN; APAYDIN, 2010). 


\section{FRAMEWORK DE INOVAÇÃO ORGANIZACIONAL NA VINÍCOLA II}

Na vinícola II, é possível verificar, em nível organizacional, uma visão e valores mais voltados e centrados nos cooperados e na sustentabilidade. Ela tem uma estrutura formal, centralizada, com muitos empregados e cooperados. Seu investimento em $P \& D$ nos últimos anos cresceu para atender às necessidades de ganho em desempenho e qualidade, capacitando colaboradores e tendo colaboração da certificadora de orgânicos para aquisição de conhecimento e adequações. A cultura organizacional da empresa é baseada no cooperativismo, social e participativo, entre pessoas e cooperados (VALENT; SCHMIDT; MACHADO, 2014), assumindo riscos junto aos cooperados, com estratégia clara ao cooperativismo, à sustentabilidade e à alocação de recursos ao desenvolvimento e à qualificação da planta e da estrutura, compreendida como desenvolvimento organizacional, coordenações e ambiente (BARNEY, 1991).

Nas dimensões da inovação, mapeadas na vinícola II (Figura 4), iniciando pela inovação como processo, também se verifica uma inovação em nível de firma, já que se encontra em todos os níveis da empresa, gerencial, produtivo e cooperados. 
Figura 4: Framework de inovação organizacional da Vinícola II
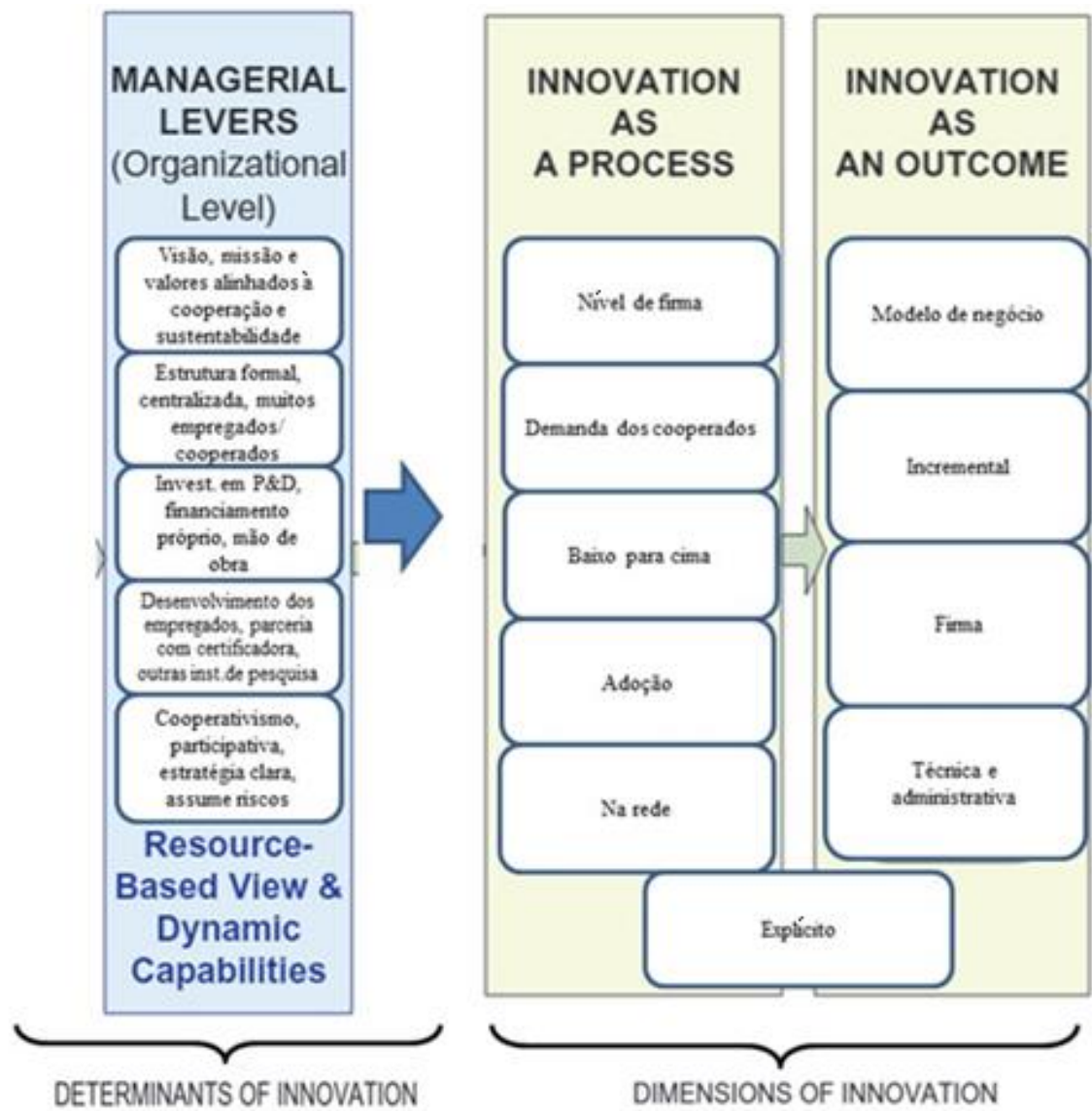

Fonte: Adaptada de Crossan e Apaydin (2010, p. 1167).

No caso da vinícola II, a inovação partiu de baixo para cima - cooperados à alta gerência -, dado que está no planejamento estratégico da empresa e em seus valores o cooperativismo, atendendo, assim, à demanda dos cooperados. A dimensão fonte é apresentada como na primeira vinícola, uma adoção de inovação, já que já existia anteriormente o vinho orgânico e o processo de produção, porém foi uma tomada de decisão aberta, ou seja, em rede (conjunto).

Assim como na vinícola I, a natureza da inovação é explícita, visto que se baseia em regras, sendo também uma inovação no modelo de negócio, incrementada em processos referentes à firma e também uma inovação técnica e administrativa. 


\section{CONSIDERAÇÕES FINAIS}

Esta pesquisa teve o objetivo de mapear as dimensões da inovação das vinícolas orgânicas certificadas a partir da visão baseada em recursos. A partir disso, foi possível perceber que as duas vinícolas apresentadas se comportam de forma semelhante em relação à inovação como resultado. Já na visão de inovação como processo, as vinícolas apresentaram muitas diferenças quanto às dimensões.

Na dimensão forma, ambas demonstraram inovar em seu modelo de negócio, tendo em vista que a adoção da produção orgânica necessitou mais do que mudanças no processo, pois a gestão foi alterada para que a certificação fosse obtida. Para isso, as vinícolas recorreram a pesquisas, buscando entender como seria viável essa implementação somada à produção convencional. Com relação à magnitude, as vinícolas inovaram de forma incremental, pois, embora tenha sido algo novo para a empresa, o conhecimento a respeito de vinhos possibilitou a implementação da nova linha com modificações, as quais não foram rompantes. Com relação à referência, as duas empresas inovaram internamente, ou seja, o sistema produtivo já era aplicado por outras firmas, que, igualmente, modificaram seu modelo de negócio; no entanto, essas empresas ainda haviam comercializado vinhos orgânicos, o que foi novidade para elas. 0 tipo de inovação foi administrativo e técnico, pois ambas precisaram rever sua estrutura e funções. Além disso, foi necessário integrar um novo sistema produtivo ao convencional. Como ambas utilizaram o conhecimento já disponível no mercado a respeito da produção orgânica, o tipo foi considerado de natureza explícita.

Considerando a inovação como processo, algumas diferenças foram apresentadas em relação às duas vinícolas. Ambas inovaram em nível de firma, pois a inovação se deu em toda a estrutura da empresa, passando por todos. A Vinícola I teve como driver da inovação a demanda do mercado (externo), pois identificou que os consumidores estavam dispostos a consumir produtos orgânicos. Já a Vinícola II foi impulsionada pelos cooperados (interno), que estavam preocupados com a sua própria saúde e com a de seus familiares; dessa forma, a alta direção aceitou a ideia desse tipo de consumo e o implementou. Por consequência, a direção da inovação na Vinícola I foi de cima para baixo (demanda da alta direção); já a Vinícola II teve a demanda de seus colaboradores de baixo para cima. Com relação à dimensão fontes, a Vinícola I adotou uma inovação, 
já que a demanda foi externa. Na Vinícola II, no entanto, a fonte é considerada ideação, assim, por causa da demanda interna, eles decidiram implementá-la. Com relação ao locus, a Vinícola I teve no nível de firma (fechado), pois decidiu internamente e contratou serviços já especializados. Já a Vinícola II inovou em nível de rede (aberta), pois alguns de seus fornecedores adotaram essa inovação também e ela não contratou apenas aqueles que já eram orgânicos anteriormente. Da mesma forma que na inovação vista como resultado, aqui a dimensão natureza também se mostrou explícita.

Nesse cenário apresentado, pode-se perceber que a motivação para inovar foi diferente, tendo em vista que a Vinícola I buscou um espaço no mercado, enquanto a Vinícola II buscou atender à demanda de seus cooperados. Dessa forma, os recursos necessários e os recursos disponíveis foram diferentes, considerando as duas vinícolas, tendo em vista o modelo que cada uma adotou.

Sendo assim, considera-se que a limitação desta pesquisa está na consideração apenas da análise baseada em recursos, sem considerar o impacto dos demais determinantes (leadership e business processes) nas dimensões da inovação apresentadas. Dessa forma, sugere-se como estudos futuros a análise das demais determinantes da inovação proposta por Crossan e Apaydin (2010), visto que este estudo se propôs a analisar apenas a managerial levers.

\section{REFERÊNCIAS BIBLIOGRÁFICAS}

ALTIERI, M. A. Agroecologia: a dinâmica produtiva da agricultura sustentável. 5. ed. Porto Alegre: Editora da Universidade Federal do Rio Grande do Sul, 2008.

ASSAD, M. L. L.; ALMEIDA, J. Agricultura e Sustentabilidade: contextos, desafios e cenários. Ciência \& Ambiente, Santa Maria, n. 29, p. 21-22, 2004. Disponível em: <http://www.ufrgs.br/pgdr/arquivos/427.pdf>. Acesso em: 17 set. 2017.

ASSIS, R. L. de; ROMEIRO, A. R. Agroecologia e Agricultura Orgânica: controvérsias e tendências. Desenvolvimento e Meio Ambiente, Curitiba, v. 6, p. 67-80, 2002.

AZEVEDO, E.; PELICIONI, M. C. F. Promoção da saúde, sustentabilidade e agroecologia: uma discussão intersetorial. Saúde \& Sociedade, São Paulo, v. 20, n. 3, p. 715-729, 2011. 
BARNEY, J. Firm resources and sustained competitive advantage. Journal of Management, v. 17, n. 1, p. 99-120, 1991.

BENEVIDES, L. HowStuffWorks: Como funciona a agricultura orgânica. Publicado em 03 out. 2007 [atualizado em 16 jun. 2008]. Disponível em: <http://ambiente. hsw.uol.com.br/agricultura-organica2.html>. Acesso em: 17 ago. 2015.

BRASIL. Lei no 5.764, de 16 de dezembro de 1971. Define a Política Nacional de Cooperativismo, institui o regime jurídico das sociedades cooperativas e dá outras providências. Diário Oficial [da] República Federativa do Brasil. Brasília, DF, 16 dez. 1971. Disponível em: <http://www.planalto.gov.br/ccivil_03/leis/L5764. htm>. Acesso em: 17 set. 2017.

BRASIL. Lei no 10.831, de 23 de dezembro de 2003. Dispõe sobre a agricultura orgânica e dá outras providências. Diário Oficial [da] República Federativa do Brasil. Brasília, DF, 24 dez. 2003. Disponível em: <http://www.planalto.gov.br/ ccivil_03/leis/2003/L10.831.htm>. Acesso em: 17 set. 2017.

BRASIL. Decreto no 6.323, de 27 de dezembro de 2007. Regulamenta a Lei no 10.831, de 23 de dezembro de 2003, que dispõe sobre a agricultura orgânica, e dá outras providências. Diário Oficial [da] República Federativa do Brasil. Brasília, DF, 28 dez. 2007. Disponível em: <https://www.planalto.gov.br/ccivil_03/_ato2007-2010/2007/decreto/d6323.htm>. Acesso em: 17 set. 2017.

BUTTENBENDER, P. L. O Agronegócio Cooperativo. In: SPAREMBERGER, A.; BUTTENBENDER, P. L.; ZAMBERLAN, L. (Orgs.). Princípios de Agronegócios: conceitos e estudos de casos. ljuí: Unijuí, 2010, p. 71-98.

CAPORAL, F. R.; COSTABEBER, J. A. Agroecologia e Desenvolvimento Rural Sustentável: perspectivas para uma nova Extensão Rural. Agroecologia $e$ Desenvolvimento Rural Sustentável, v. 1, n. 1, p. 16-37, jan./mar. 2000.

CAPORAL, F. R.; COSTABEBER, J. A. Agroecologia e Extensão Rural: Contribuições para a Promoção do Desenvolvimento Rural Sustentável. Publicação on-line. Publicado em 2004. Disponível em: <http://www.emater.tche.br/site/arquivos_pdf/teses/agroecologia\%20e\%20extensao\%20rural\%20contribuicoes\%20 para\%20a\%20promocao\%20de\%20desenvolvimento\%20rural\%20sustentavel. pdf > Acesso em: ago. 2015.

CASAGRANDE JUNIOR, E. F. Inovação tecnológica e sustentabilidade: possíveis ferramentas para uma necessária interface. Revista Educação \& Tecnologia, Curitiba, n. 8, p. 97-109, 2004. Disponível em: <http://static2.inovacaoedesign. 
com.br/artigos_cientificos/inovacaotecnologica_sustentabilidade.pdf>. Acesso em: 16 ago. 2015.

CONFEDERAÇÃO NACIONAL DA INDÚSTRIA - CNI. Mapa estratégico da indústria 2013-2022. Brasília: CNI, 2013.

CROSSAN, M. M.; APAYDIN, M. A multi-dimensional framework of organizational innovation: a systematic review of the literature. Journal of Management Studies, v. 47, n. 6, set. 2010.

DELARMELINA, N.; SALLES, A. O. T. Um estudo sobre a natureza das cooperativas agropecuárias sob a ótica da teoria dos custos de transação. In: ENCONTRO DE ECONOMIA CATARINENSE, 8., 2014, Rio do Sul. Anais... Rio do Sul, SC: APEC/UNIDAVI, 2014, p. 5-25. Disponível em: <http://www.apec.unesc.net/VIII_EEC/sessoes_tematicas/8\%20-\%20Economia\%20Rural/UM\%20ESTUDO\%20SOBRE\%20 A\%20NATUREZA\%20DAS\%20COOPERATIVAS\%20AGROPECU\%C3\%81RIAS.pdf> Acesso em: 17 set. 2017.

FARINA, E. M. M. Q. Padronização em sistemas agroindustriais. In: ZYLBERSZTAJN, D.; SCARE, R. F. (Orgs.). Gestão de qualidade no agribusiness: estudos e casos. São Paulo: Atlas, 2003, p. 18-29.

FLEURY, A.; FLEURY, M. T. L. Aprendizagem e Inovação Organizacional: As experiências de Japão, Coreia e Brasil. São Paulo: Atlas, 1995. 237 p.

GIL, A. C. Métodos e Técnicas de Pesquisa Social. São Paulo: Atlas S.A., 2008.

GLIESSMAN, S. R. Agricultura e Sustentabilidade: problemas e alternativas. Porto Alegre: UFRGS, 2009.

GOLLO, S. S.; CASTRO, A. W. V. de. O processo de inovação e de estratégias de cooperação competitiva para a obtenção da indicação de procedência Vale dos Vinhedos: o caso da vinícola boutique Lídio Carraro - Serra Gaúcha, RS/Brasil. Rio Branco: Sociedade Brasileira de Economia/Administração e Sociologia Rural, 2008.

HALWEIL, B. Can Organic Farming Feed Us All? World Watch Magazine, v. 19, n. 3, may/june 2006. Disponível em: <http://www.worldwatch.org/node/4060>. Acesso em: 17 set. 2017.

HAYASHI JUNIOR, P. O uso de recursos na criação de vinhos ícones e a cocriação de valor. Porto Alegre: UFRGS, 2011. 
INTERNATIONAL CO-OPERATIVE ALLIANCE - ICA. Co-operative identity, values \& principles. [On-line. Sem data de Publicação]. Disponível em: <http://www.ica. coop/ica/pt/ptprinciples.html>: Acesso em: 17 set. 2017.

KLEDAL, P. R. The Political Economy of Organic Foods. Organic Eprints. Última modificação em 12 abr. 2010. Disponível em: <http://orgprints.org/1576/>. Acesso em: 17 set. 2017.

MALHOTRA, N. Pesquisa em marketing: uma orientação aplicada. 4. ed. Tradução de Laura Bocco. Porto Alegre: Boookman, 2006.

MELLO, L. M. R. de. Desempenho da vitivinicultura brasileira em 2015. Embrapa. Publicado em 16 fev. 2016. Disponível em: <https://www.embrapa.br/en/busca-de-noticias/-/noticia/9952204/artigo-desempenho-da-vitivinicultura-brasileira-em-2015>. Acesso em: 17 set. 2017.

MOBILIZAÇÃO EMPRESARIAL PELA INOVAÇÃO - MEI. Mobilização empresarial pela inovação: estratégia e objetivos. Publicado em 2011. Disponível em: <http://inova.sistemafindes.org.br/Arquivos/Downloads/18/MEl\%20-\%20Estrategias\%20e\%200bjetivos.pdf>. Acesso em: 16 maio 2014.

NAGANO, M. S.; STEFANOVITZ, J. P.; VICK, T. E. Innovation management processes, their internal organizational elements and contextual factors: an investigation in Brazil. Journal of Engineering and Technology Management, v. 33, p. 63- 92, 2014.

NODARI, R. O.; GUERRA, M. P. A agroecologia: estratégias de pesquisa e valores. Estudos Avançados, v. 29, n. 83, 2015. [on-line]

ORGANISATION INTERNATIONALE DE LA VIGNE ET DU VIN - OIV. Elements de conjoncture mondiale. Paris: [s.n.], 2016. Disponível em: <http://www.oiv.int/ public/medias/4567/oiv-noteconjmars2016-fr.pdf>. Acesso em: 17 set. 2017.

OSENIEKS, J.; BABAUSKA, S. The relevance of innovation management as prerequisite for durable existence of small and medium enterprises. Procedia Social and Behavioral Sciences, v. 110, p. 82-92, 2014.

OSTERWALDER, A. The Business Model Otology: A Proposition in a Design Science Approach. 2004. 172 f. Thèse (Docteur en Informatique de Gestion) Universite de Lausanne, Lausanne, 2004.

POPADIUK, S., CHOO, C. W. Innovation and knowledge creation: How are these concepts related? International Journal of Information Management, v. 26, n. 4, p. 302-312, ago. 2006. 
REDCLIFT, M.; GOODMAN, D. The machinery of hunger: the crisis of Latin America food systems. In: GOODMAN, D.; REDCLIFT, M. (Eds.). Environment and Development in Latin America. Inglaterra: Manchester University Press, 1991. Disponível em: <https://books.google.com.br/books>. Acesso em: 10 ago. 2015. SANS, F. X. Agroecología. Revista y técnica de ecología y medio ambiente, v. XVI, n. 1, enero, 2007.

SCHENATTO, F. J. A. Modelo dinâmico de gestão da inovação tecnológica: uma abordagem contextualizada ao ciclo de vida da organização. 2003. 89 f. Dissertação (Mestrado em Engenharia de Produção) - Universidade Federal de Santa Catarina, Florianópolis, 2003. Disponível em: <https://repositorio.ufsc. $\mathrm{br} /$ bitstream/handle/123456789/85179/197209.pdf\%3Fsequence\%3D1+\&c$\mathrm{d}=3 \& \mathrm{hl}=\mathrm{pt}-\mathrm{BR} \& \mathrm{ct}=\mathrm{clnk} \& \mathrm{gl}=\mathrm{br}>$. Acesso em: 20 maio 2014.

THE ORGANISATION FOR ECONOMIC CO-OPPERATION AND DEVELOPMET OECD. Manual de Oslo: Diretrizes para coleta e interpretação de dados sobre inovação. Brasília: [s.n.], 2005.

TIDD, J.; BESSANT, J.; PAVITT, K. Gestão da inovação. 3. ed. Porto Alegre: Bookman, 2008.

TIDD, J.; BESSANT, J.; PAVITT, K. Managing innovation, integration technological, market and organizational change. West Sussex: John Wiley \& Sons, 2005.

VALENT, J. Z.; SCHMIDT, V.; MACHADO, J. A. D. O processo decisório na transição agroecológica dos agricultores da cooperativa leoboqueirense de agricultores familiares. 2014. 98 f. Dissertação (Mestrado em Agronegócio) - Universidade Federal do Rio Grande do Sul, Porto Alegre, 2014. Disponível em: <http://www. lume.ufrgs.br/handle/10183/97861>. Acesso em: 20 jul. 2015.

WONG, S.; CHIN, K. Organizational innovation management. Industrial Management \& Data Systems, v. 107, n. 9, p. 1290-1315, nov. 2007.

ZEN, A. C.; FRACASSO, E. M. A influência dos recursos e das competências na inovação: um estudo de múltiplos casos na indústria eletrônica gaúcha. 2007. 139 f. Dissertação (Mestrado em Administração) - Universidade Federal do Rio Grande do Sul, Porto Alegre, 2007.

ZEN, A. C.; FRACASSO, E. M. Recursos, competências e capacidade de inovação: um estudo de múltiplos casos na indústria eletro-eletrônica no Rio Grande do Sul. Revista de Administração e Inovação, São Paulo, v. 9, n. 4, p. 177-201, out./ dez. 2012. 